\begin{tabular}{cc}
\hline & International Journal of Engineering \& Technology, $7(4.30)(2018) 213-217$ \\
SPC & International Journal of Engineering \& Technology \\
\hline
\end{tabular}

\title{
Effect of Annealing Temperature of Cugao 2 thin Films by Using RF Magnetron Sputtering Technique on Optical and Structural Properties
}

\author{
Lam Wai Yip 1 , Afishah Alias", Asmahani Binti Awang³, Abu Bakar Bin Abd Rahman ${ }^{4}$, Khairul Anuar Bin \\ Mohamad $^{5}$, Nafarizal Bin Nayan', Chee Fuei Pien ${ }^{7}$, Siti Ashraf Abdullah \\ 1,3,4,7 Faculty of Science and Natural Resources, Universiti Malaysia Sabah, 88400, Kota Kinabalu, Sabah, Malaysia \\ ${ }^{2}$ Faculty of Applied Science and Technology, Universiti Tun Hussein Onn Malaysia, Educational Hub Pagoh, 84600, Muar, Johor, Malaysia \\ ${ }^{5,6,8}$ Faculty of Electrical and Electronic Engineering, Universiti Tun Hussein Onn Malaysia, Johor, Malaysia \\ *Corresponding author E-mail: afishah@uthm.edu.my
}

\begin{abstract}
$\mathrm{Cu}$-based conductive oxide such as $\mathrm{CuGaO}_{2}$ is seen to be a promising transparent p-type oxide material. The study of p-type semiconductor $\mathrm{CuGaO}_{2}$ thin films have been carried out to investigate the effects of different parameters in providing the optimum result in achieving good optical transparency and conductivity of the thin film. The $\mathrm{CuGaO}_{2}$ thin films were fabricated on quartz substrate via the Radio Frequency (RF) magnetron sputtering technique with varying substrate temperatures and different annealing temperatures. The p-type thin films were deposited at a temperature ranging from room temperature, $100^{\circ} \mathrm{C}, 200^{\circ} \mathrm{C}$ and $300^{\circ} \mathrm{C}$. The samples were also annealed varying from temperature of $500^{\circ} \mathrm{C}, 600^{\circ} \mathrm{C}, 700^{\circ} \mathrm{C}$ and $800^{\circ} \mathrm{C}$. The fabricated sample were characterized using X-ray diffraction (XRD), UV-Visible spectroscopy, and atomic force microscope ( $\mathrm{afm})$. XRD showed a peak at $2 \theta=36.10^{\circ}(012)$. The optical transparency values achieved from UV-Vis spectrometer were seen to be approximately $80 \%$ and the bandgaps were found to be in the range of 3.34-3.43 eV which is in line with the bandgap value from the research on $\mathrm{CuGaO}_{2}$ thin films. From the afm, the mean surface roughness increases with increasing temperature and this is due to the increment of grain size. The highest grain size was observed at substrate temperature of $200^{\circ} \mathrm{C}$.
\end{abstract}

Keywords: Annealing Temperature; $\mathrm{CuGaO}_{2} ; \mathrm{RF}$ Magnetron Sputtering; Thin Films.

\section{Introduction}

The electronic industry has been well received by the current generation. Optoelectronics have intrigued the interest of many especially researchers due to its potential and demand in the marketplace. The basic electronic applications like LCD TV, mobile phones, electronic tablets and laptops have been the typical necessities in most societies we live in nowadays. Transparent Conductive Oxides (TCO) have been widely used not just due to its transparent properties but also their electrical properties in relevant devices which are commonly used in technological applications such as LEDs [1], flat panel displays [2], sensors [3] and transistors [4], which forms the basis of the optoelectronic industry. Most of the TCOs used are of the n-type semiconductors due to its good electrical properties such as $\mathrm{SnO}_{2}$ [4], $\mathrm{In}_{2} \mathrm{O}_{3}$ [5] and $\mathrm{ZnO}$ [6]. In fabricating a TCO p-n junction diode, a good n-type and p-type TCO are needed. However, p-type conductivities are of several orders lower than the n-type semiconductors. The delafossite group was reviewed and showed potential in improving the p-type conductivities. Several p-types of the delafossite group such as $\mathrm{CuAlO}_{2}$ [7] and $\mathrm{CuInO}_{2}$ [8] and $\mathrm{CuGaO}_{2}$ [3]. $\mathrm{CuGaO}_{2}$ belongs to a p-type semiconductor group called the delafossite structure where is it has the formula of $\mathrm{AMO}_{2}$ [9]. However, there were only few studies on the delafossite B-site cation Ga [2]. Previous studies emphasized on the effects of lower temperature post- treatment of the $\mathrm{CuGaO}_{2}$ thin film, which were also limited with the use of glass that has a threshold of $550^{\circ} \mathrm{C}$ [10]. In this research, RF magnetron sputtering was used to deposit the $\mathrm{CuGaO}_{2}$ thin films onto quartz with the effects of higher annealing temperature. The parameters involve different sputtering temperature and different annealing temperature in studying the effect on the thin film crystal structure. Post annealing improves the crystal structure of the $\mathrm{CuGaO}_{2}$.

\section{Research approach}

$\mathrm{CuGaO}_{2}$ target used in this experiment was of a purity of $99.99 \%$, which was purchased from Stanford Material Corporation. The quartz substrates were cleaned using distilled water, acetone, methanol, ethanol and then distilled water again in an orderly manner for 15 minutes, all in an ultrasonic bath. Once the substrate was prepared, the deposition of $\mathrm{CuGaO}_{2}$ thin films proceeded using RF magnetron sputtering. Pre-sputtering was first initiated before the fabrication of the samples. The pre-sputtering process was to eradicate contamination found on the target surface. The $\mathrm{CuGaO}_{2}$ thin films were then deposited on quartz substrates at different sputtering temperature from room temperature, $100^{\circ} \mathrm{C}$, $200^{\circ} \mathrm{C}$ and $300^{\circ} \mathrm{C}$. Each sputtering process was 30 minutes long. Post annealing was performed with various temperatures on the samples of different sputtering temperature from $500^{\circ} \mathrm{C}, 600^{\circ} \mathrm{C}$, $700^{\circ} \mathrm{C}$ and $800^{\circ} \mathrm{C}$. Atomic force microscopy (afm) was used to 
evaluate the surface roughness. The structural and optical properties were characterized using X-Ray Diffraction Philips Expert Pro and UV-Vis Spectrometer Lambda EZ210.

\subsection{Substrate cleaning}

In cleaning the substrates, the sonicator is used to ensure an even and thorough wash of the substrates using acetone, isopropyl alcohol (IPA) and distilled water. Then, it is followed by using the nitrogen spraying method to dry the substrate prior sputtering [11]

In this research, the quartz slabs were cut into a $2.5 \mathrm{~cm} \times 2 \mathrm{~cm}$ dimension before the cleaning process. The substrates then undergone a consecutive 15 minutes ultrasonic bath using distilled water, acetone, methanol, ethanol, and distilled water again. The substrates were then blown with nitrogen gas to dry in a clean chamber. The purpose of the alcohol is to ensure organic stains on the surface of the substrates are largely removed.

\subsection{Radio frequency (RF) magnetron sputtering}

$\mathrm{CuGaO}_{2}$ target used in this experiment comes with a purity of 99.99\%, which was purchased from Stanford Material Corporation. Throughout the process of handling the substrates, latex gloves must be worn to avoid further contamination on the surface of the substrates.

The sputtering chamber was then pumped until it reaches $7.0 \times 10$

${ }^{6}$ Torr. The target was left to sputter for 10 minutes prior exposing the substrate to the process. Reason for the pre-sputtering process was to eradicate contamination found on the target surface. The RF power was set at $100 \mathrm{~W}$ and $80 \mathrm{sccm}$ of argon gas was used as sputtering gas. The substrates were rotated at a speed of $5 \mathrm{rpm}$. In addition, the working pressure was approximately $4.0 \times 10^{-3}$ Torr. The finishing touch was to have the samples annealed at $500^{\circ} \mathrm{C}$, $600^{\circ} \mathrm{C}, 700^{\circ} \mathrm{C}$ and $800^{\circ} \mathrm{C}$ for three hours with a ramp rate of $100^{\circ} \mathrm{C}$ per minute.

\subsection{UV-Vis spectroscopy analysis}

The optical bandgap $\left(E_{g}\right)$ can be obtained first by calculating the absorption coefficient $(\alpha)$ of the thin films by using the following equation:

$$
\alpha=(1 / d) \ln (1 / T)
$$

where $\mathrm{d}$ is the film thickness and $\mathrm{T}$ is the transmittance of the film.

$(a h v)^{1 / n}=A\left(h v-E_{g}\right)$

Where $\mathrm{A}$ is the absorption edge width parameter and hv which indicates the incident photon energy. The symbol $n$ is either $1 / 2$ or 2 depending if it is direct allowed transition or indirect allowed transition [12].

\section{Results and Discussion}

\subsection{X-Ray Diffraction Spectroscopy (XRD)}

Figure 1 shows the XRD pattern for the samples produced. The samples were then annealed at temperature of $500,600^{\circ} \mathrm{C}, 700^{\circ} \mathrm{C}$ and $800^{\circ} \mathrm{C}$. From Figure 1, we can observe that the peak is seen at approximately $2 \theta=36.10^{\circ}$ at annealing temperature of $800^{\circ} \mathrm{C}$ for all sputtering temperatures. Hence, the results shown indicates that the peak is achieved only at annealing temperature of $800^{\circ} \mathrm{C}$ at the orientation of (012) [13]. The rest of the XRD peaks are not significant from annealing temperature of $500,600^{\circ} \mathrm{C}, 700^{\circ} \mathrm{C}$, includ- ing the non-annealed samples (non-A). Reason being for no significant peaks is because the XRD graphs are in the amorphous state due to insufficient thermal energy in orientating the position of the atoms on the substrate surface for nucleation to happen [7].
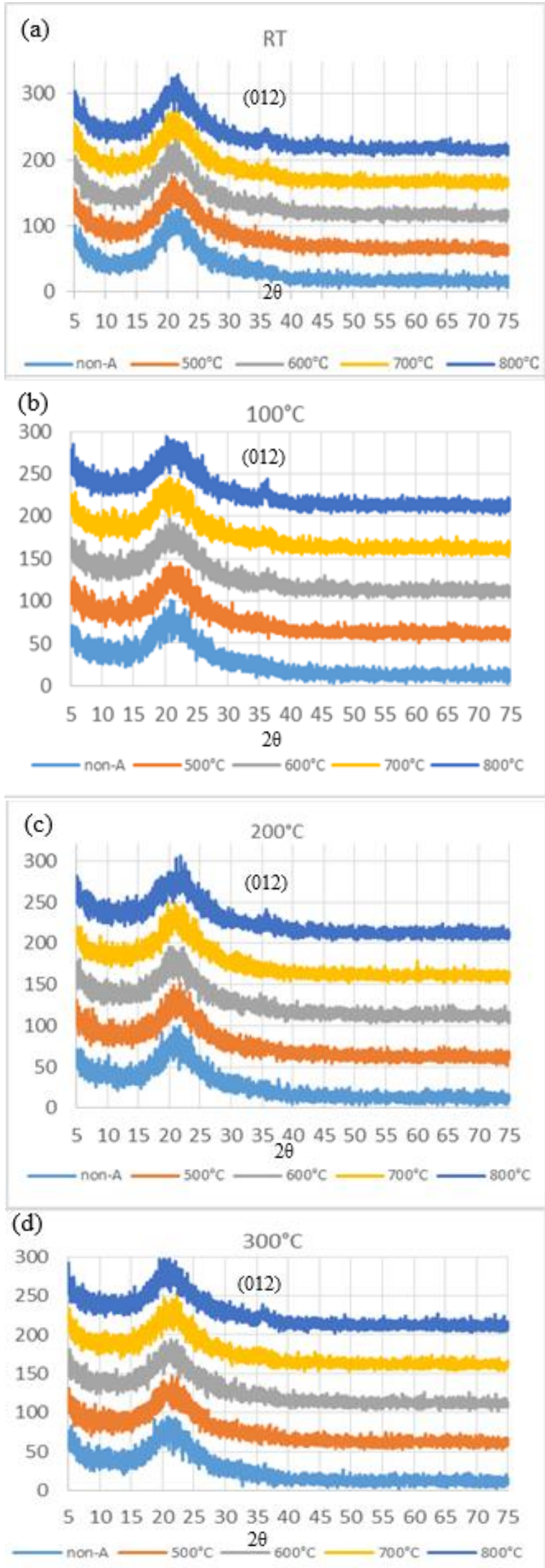

Fig. 1: XRD patterns of the thin films for sputtering temperature of (a) Room Temperature (RT), (b) $100^{\circ} \mathrm{C}$, (c) $200^{\circ} \mathrm{C}$ and (d) $300^{\circ} \mathrm{C}$ with various annealing temperature from $500,600^{\circ} \mathrm{C}, 700^{\circ} \mathrm{C}$ and $800^{\circ} \mathrm{C}$, including a non-annealed sample (non-A) 
Table 1: Grain Size of $\mathrm{CuGaO}_{2}$ thin films of different sputtering temperature with post annealing temperature of $800^{\circ} \mathrm{C}$

\begin{tabular}{|c|c|c|}
\hline $\begin{array}{c}\text { Substrate } \\
\text { Temperature }\left({ }^{\circ} \mathrm{C}\right)\end{array}$ & FWHM & Grain Size (nm) \\
\hline RT & 0.26457 & 5.5 \\
\hline 100 & 0.095833 & 15.2 \\
\hline 200 & 0.075077 & 19.4 \\
\hline 300 & 0.24875 & 5.9 \\
\hline
\end{tabular}

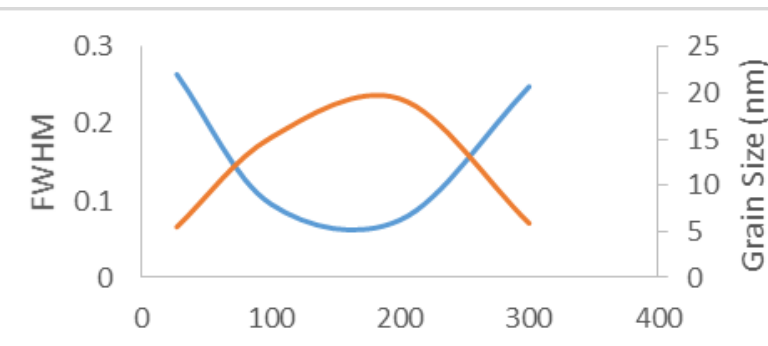

Substrate Temperature $\left({ }^{\circ} \mathrm{C}\right)$

$$
\text { - FWHM } \quad \text { Grain Size }(\mathrm{nm})
$$

Fig. 2: Grain size for $\mathrm{CuGaO}_{2}$ thin film deposited at room temperature (RT), $100^{\circ} \mathrm{C}, 200^{\circ} \mathrm{C}$ and $300^{\circ} \mathrm{C}$ with annealing temperature of $800^{\circ} \mathrm{C}$

Since the XRD patterns for annealing temperature $800^{\circ} \mathrm{C}$ showed significant peaks, hence the samples of annealing temperature $800^{\circ} \mathrm{C}$ was studied specifically. The grain size of the thin films were seen to be increasing with temperature from room temperature (RT) towards $200^{\circ} \mathrm{C}$ before dropping sharply at $300^{\circ} \mathrm{C}$. At lower substrate temperature, the atoms deposited are condensed and stuck in the region, forming small nuclei and clusters which leads to the smaller grain size. At higher substrate temperature, the mobility of the surface atoms and the cluster formation have increased, hence the larger grain size [14].

\subsection{UV-Visible Spectroscopy (UV-Vis)}

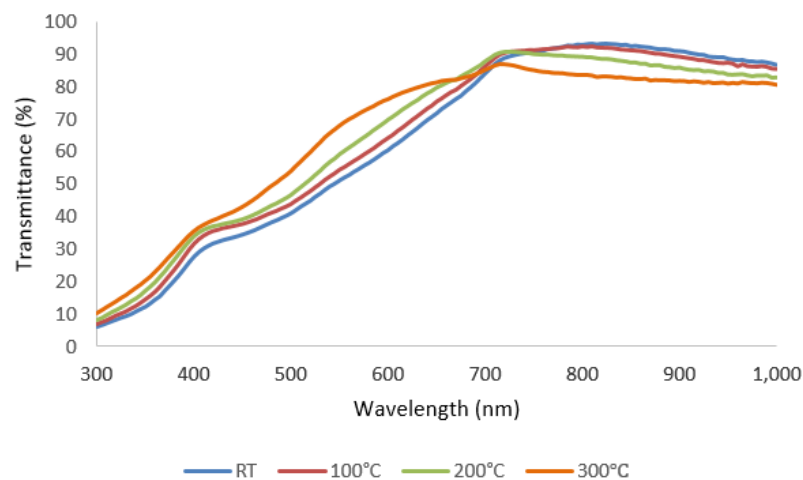

Fig. 3: Optical transmittance for $\mathrm{CuGaO}_{2}$ thin film deposited at room temperature $(\mathrm{RT}), 100^{\circ} \mathrm{C}, 200^{\circ} \mathrm{C}$ and $300^{\circ} \mathrm{C}$ with annealing temperature of $800^{\circ} \mathrm{C}$

Transmittance of the $\mathrm{CuGaO}_{2}$ thin film is approximately $80 \%$. Due to good structual homogeneity and crystallinity of the film, hence the high transparency [15]. As the sputtering temperature increases, it is observed that the absorption edge of $\mathrm{CuGaO}_{2}$ thin film shifts to the shorter wavelengths. Reason for the better transmittance at higher temperature is due to better crystal arrangement than that of the lower temperature and also because light passing through the thin films are less scattered [10].

The plot of $(a h v)^{2}$ versus $h v$ of the thin films are as shown below. The extrapolating of the linear line helped determine the optical band gap from the graph.
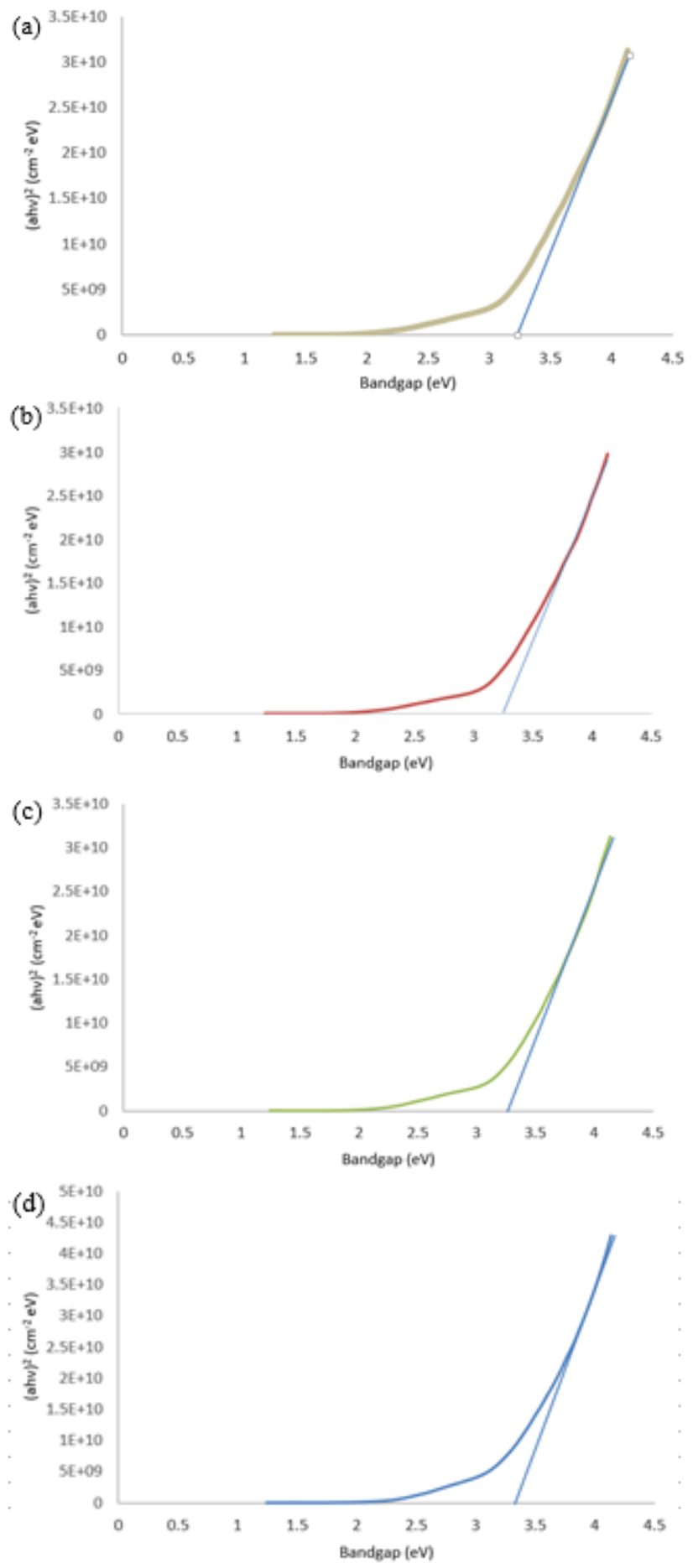

Fig. 4: Tauc plots of $\mathrm{CuGaO}_{2}$ thin films at temperature (a) room temperature, (b) $100^{\circ} \mathrm{C}$, (c) $200^{\circ} \mathrm{C}$ and $\quad$ (d) $300^{\circ} \mathrm{C}$ with annealing temperature of $800^{\circ} \mathrm{C}$ to determine the bandgap

Table 2: Bandgaps of $\mathrm{CuGaO}_{2}$ thin films of different sputtering temperature with post annealing temperature of $800^{\circ} \mathrm{C}$

\begin{tabular}{|c|c|}
\hline Substrate Temperature & Bandgap (eV) \\
\hline Room Temperature & 3.34 \\
\hline $100^{\circ} \mathrm{C}$ & 3.35 \\
\hline $200^{\circ} \mathrm{C}$ & 3.40 \\
\hline $300^{\circ} \mathrm{C}$ & 3.43 \\
\hline
\end{tabular}

he bandgaps were determined from the calculation using Tauc equation and observation from the Tauc plots. As the substrate temperature increases, so does the bandgap of the substrates. This is a Moss-Burstein effect where the bandgap of the film is increased as the absorption edge is pushed to higher energy state due to some states close to the conduction band being populated. 


\subsection{Atomic Force Microscopy (AFM)}
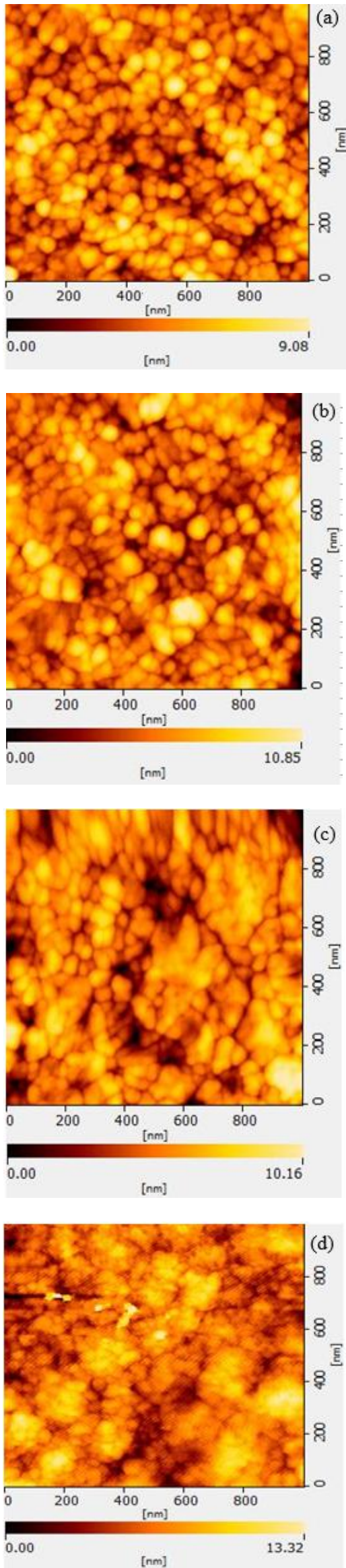

Fig. 5: $\mathrm{AFM}$ for $\mathrm{CuGaO}_{2}$ thin film deposited at (a) room temperature (RT), (b) $100^{\circ} \mathrm{C}$, (c) $200^{\circ} \mathrm{C}$ and (d) $300^{\circ} \mathrm{C}$ with annealing temperature of $800^{\circ} \mathrm{C}$
Table 3: Mean roughness of $\mathrm{CuGaO}_{2}$ thin films of different sputtering temperature with post annealing temperature of $800^{\circ} \mathrm{C}$

\begin{tabular}{|c|c|}
\hline Substrate Temperature & $\begin{array}{c}\text { Average Surface Roughness } \\
(\mathbf{n m})\end{array}$ \\
\hline Room Temperature & $5.170 \times 10^{-3}$ \\
\hline $100^{\circ} \mathrm{C}$ & $2.357 \times 10^{-3}$ \\
\hline $200^{\circ} \mathrm{C}$ & $4.830 \times 10^{-1}$ \\
\hline $300^{\circ} \mathrm{C}$ & $2.348 \times 10^{-1}$ \\
\hline
\end{tabular}

As observed from Figure 5 of the different sputtering temperatures, as the temperature is increased from room temperature (RT), $100^{\circ} \mathrm{C}, 200^{\circ} \mathrm{C}$ and $300^{\circ} \mathrm{C}$, the grain-like particles becomes more "fused" as they are closely packed and densely arranged. This possible phenomenan may be due to the nature of the rhombohedral structure of the faces of the $\mathrm{CuGaO}_{2}$ crystal [16]. Hence, we observed from the average surface roughness in Table 3 that as the substrate temperature increases, the average surface roughness also increases with increasing grain size [17].

\section{Conclusion}

It is seen that there was no significant peak for the annealed thin films except that of the $800^{\circ} \mathrm{C}$ on the quartz substrate. This is likely due to the thin films being in an amorphous state. The transmittance were seen to be approximately $80 \%$ as the absorption edges of $\mathrm{CuGaO}_{2}$ thin films shift to the shorter wavelengths. The optical bandgaps were measured in the range from $3.34 \mathrm{eV}$ to $3.43 \mathrm{eV}$. The grain-like particles become more closely packed and the average surface roughness increases with increasing sputtering temperature.

\section{Acknowledgement}

The author is grateful to Universiti Malaysia Sabah and Universiti Tun Hussein Onn Malaysia for providing relevant instruments in conducting this research. This research is funded by the UMS GREAT grant (GUG0017-SG-M-1/2016).

\section{References}

[1] Tsukazaki A, Ohtomo A, Onuma T, Ohtani M, Makino T, Sumiya M, Ohtani K, Chichibu SF, Fuke S \& Segawa Y (2004), Repeated Temperature Modulation Epitaxy for p-type Doping and LightEmitting Diode Based on ZnO. Nat. Mater. 4, 42-46.

[2] R. Bruce G, Nathan A, Meagan AM, Xiaoli T \& David PC (2005), Synthesis, microstructure, and electrical properties of the delaffosite compound $\mathrm{CuGaO}_{2}$. Journal of Alloys and Compounds 391, 262-266

[3] Alias A, Mohamad KA, Gosh BK, Sakamoto M \& Uesugi K (2012), Fabrication of $\mathrm{CuGaO}_{2}$ Films by Sol-gel Method for UV Detector Application. IEEE-ICSE2012. 2, 763-765.

[4] Presley RE, Munsee CL, Park CH, Hong D, Wager JF \& Keszler DA (2004), Tin Oxide transparent thin-film transistors. Journal of Physics D: Applied Physics 37, 20.

[5] Sahm T, Gurlo A, Barsan N \& Weimar U (2007), Properties of Indium Oxide Semiconducting Sensors Deposited by Different Techniques. Particulate Science and Technology 24, 441-452.

[6] Dhara, S, \& Giri PK (2012), Stable p-Type Conductivity And Enhanced Photoconductivity From Nitrogen-doped Annealed $\mathrm{ZnO}$ Thin Film. Thin Solid Films. 520(15), 5000-5006.

[7] Reddy AS, Park HH, Rao GM, Uthanna S \& Reddy PS (2009), Effect of Substrate Temperature on the Physical Properties of DC Magnetron Sputtered $\mathrm{CuAlO}_{2}$ Films. Journal of Alloys and Compounds 474(1-2), 401-405.

[8] Sasaki M \& Shimode M (2003), Fabrication of Bipolar $\mathrm{CuInO}_{2}$ with Delafossite Structure. Journal of Physics and Chemistry of Solids 64(9), 1675-1679.

[9] Liu Q, Liu Z, Chen J, Feng L \& Tian H (2011), First-principles Study of Structural, Mechanical, Electronic and Optical Properties of 3R- and 2H- $\mathrm{CuGaO}_{2}$. Physica B. 406, 3377-3382.

[10] Abu Bakar MH, Lam ML, Mohamad KA, Sulaiman S, Salleh S \& Alias A (2015), Influence of Substrate Temperature and Post An- 
nealing of $\mathrm{CuGaO}_{2}$ Thin Films on Optical and Structural Properties. AIP Conference Proceedings 1674(020019), 1-5.

[11] Saurabh K \& Screenivas K (2016), Residual Stress and Defect Content in Magnetron Sputtered ZnO Films Grown on Unheated Glass Substrates. Current Applied Physics 16, 748-756.

[12] Haarindraprasad R, Hashim U, Gopinath SCB, Kashif M, Veeradasan P, Balakrishnan SR, Mishra YK (2015), Low Temperature Annealed Zinc Oxide Nanostructured Thin Film-Based Transducers: Characterization for Sensing Applications. PLoS ONE 10(7), $1-20$.

[13] Chien-Yie T \& Ching-Lien C. (2017), Improved Electrical Properties of p-type $\mathrm{CuGaO}_{2}$ Semiconductor Thin Films through $\mathrm{Mg}$ and Zn Doping. Journal of Ceramics International 43, 2563-2567.

[14] Mohamed JR, Sanjeeviraja C \& Amalraj L (2016). Influence of Substrate Temperature on Physical Properties of (111) oriented $\mathrm{CdIn}_{2} \mathrm{~S}_{4}$ Thin Films by Nebulized Spray Pyrolysis Technique. Journal of Asian Ceramic Societies. 4(2), 191-200.

[15] Zhang L, Huang J, Tang K, Ren B, Zhang S \& Wang L (2016), The Effects of Substrate Temperature on Properties of B and Ga Codoped $\mathrm{ZnO}$ Thin Films Grown by RF Magnetron Sputtering. Journal of Surface \& Coating Technology 20977, 1-5.

[16] Chien-Yie T \& Ching-Lien C (2017), Growth and Characterization of sol-gel derived $\mathrm{CuGaO}_{2}$ Semiconductor Thin Films for UV Photodetector Application. Journal of Crystal Growth 468, 662-665.

[17] Ghorannevis Z, Hosseinnejad MT, Habibi M \& Golmahdi P (2015) Effect of Substrate Temperature on Structural, Morphological and Optical Properties of Deposited Al/ZnO Films. Journal of Theoretical and Applied Physics 9(1), 33-38. 